\title{
Prevention of Infantile Cerebral Disease \& Fetal Demise with Novel Hypoxia Index \& FHR Score in Fetal Monitoring
}

\author{
Kazuo Maeda' ${ }^{1 *}$ and Masaji Utsu ${ }^{2}$ \\ ${ }^{1}$ Honorary Prof Obstet Gynecol, Tottori University, Japan \\ ${ }^{2}$ Department of Obstetrics Gynecology, Seirei Mikatahara Hospital, Japan
}

Submission: March 11, 2019; Published: March 19, 2019

*Corresponding author: Kazuo Maeda, Honorary Prof Obstet Gynecol, Tottori University, Japan

\section{Methods}

\section{Hypoxia index}

As the corresponding author recognized completely normal neonate, whose Apgar score was 9, after appearances of 3 connected typical late decelerations, despite the outcome must be ominous in past reports of late deceleration [1]. while frequently repeated late decelerations appeared in 50 minutes were followed by the Apgar score 3 in severe asphyxia, loss of baseline variability followed by severe brain damage. In addition in a definition, a late deceleration must repeat for more than 15 minutes before the definition.

Thus, late deceleration was ominous not by late appearance of deceleration, but frequently repeated FHR decelerations, thus, we understood the process of fetal damage, because the vagal nerve center located in medulla oblongata was stimulated and excited by the hypoxia, then develops FHR bradycardia and FHR deceleration as well as continuous fetal bradycardia depending on the duration of hypoxia, namely, FHR deceleration was a hypoxic area, thus, repeated decelerations means repeated hypoxia, and repeated hypoxia is effective to damage fetus in the repeated decelerations, thus, novel Hypoxia Index was the sum of FHR deceleration durations (min), divided by the lowest FHR (bpm) because it meant the intensity of hypoxia, and multiplied by 100 to keep the index an integer. Six cases of cerebral palsy and 16 noncerebral palsy cases, who were diagnosed in pediatric clinic were collected, and their hypoxia indices were calculated in the FHR curves recorded in intrapartum fetal monitoring and preserved in obstetric ward in retrospective studies.

The hypoxia index of all 6 cerebral palsy [2] cases were 25 or more, while the hypoxia index of all 16 non cerebral palsy cases were 24 or less, and there was significant difference of cerebral palsy cases in high and low hypoxia index groups. The $\mathrm{P}$ of $\mathrm{Chi}^{2}$ test was almost zero (Table1) (Figure 1). Infantile cerebral palsy caused by intrapartum damage is prevented when the hypoxia index is 24 or less. Parturient woman is requested to take lateral posture when a FHR deceleration appears in fetal monitoring to prevent further deceleration to prevent high hypoxia index.

Table 1: The cerebral palsy in 25 or more and 24 or less hypoxia index groups.

\begin{tabular}{|c|c|c|}
\hline \multirow{2}{*}{ Hypoxia Index } & \multicolumn{2}{|c|}{ Cerebral Palsy Cases } \\
\cline { 2 - 3 } & Yes & No \\
\hline 25 or more & 6 & 0 \\
\hline 24 or less & 0 & 16 \\
\hline
\end{tabular}

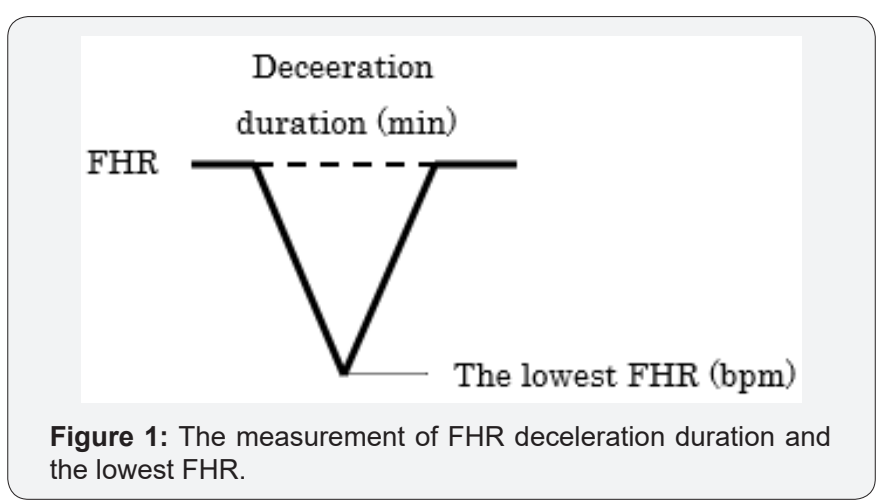

\section{FHR Score}

A mathematical FHR score is calculated in the parts FHR deceleration in every 5 minutes of fetal monitoring, which is calculated by the sum of 11 deceleration parts evaluation scores of FHR in $5 \mathrm{~min}$. The evaluation scores were calculated by the percentage of lower Apgar score than 7 in each deceleration parts of FHR. Apgar score and umbilical cord blood pH were calculated with regression equations of FHR score and Apgar score \& umbilical cord blood pH (UApH) $[3,4]$. 
For example,

\begin{tabular}{|c|c|c|}
\hline FHR Score & Apgar Score & UApH \\
\hline 10 & 6 & normal \\
\hline 15 & 4 & acidosis \\
\hline 20 & 3 & acidosis \\
\hline 24 & 0 (death) & \\
\hline
\end{tabular}

PHR score, Apgar score \& UApH are predicted even in the first stage of labor, thus, early caesarean delivery is able to be selected even in the $1^{\text {st }}$ stage of labor.

\section{Pathologic sinusoidal FHR}

A truly pathologic sinusoidal FHR caused by severe fetal anemia or heavy asphyxia should be separated from physiologic sinusoidal FHR, which is fully favorable, while its wave form is close to pathologic one. Physiologic favorable one is caused by cyclic fetal mouthing or respiratory movements and separated from pathologic one when it is recorded by actocardiogram (ACG) but not by cardiotocogram (CTG). Pathologic sinusoidal one is diagnosed by frequency spectrum analysis, namely, La/Ta ratio is more than $39 \%$ and at the same time PPSD is 300 or more in frequency spectrum analysis [5]. True pathological sinusoidal FHR fetus should receive early caesarean delivery, followed by neonatal blood transfusion, if it is caused by fetal anemia.

\section{Other techniques}

Artificial neural network computer was able to diagnose the probability to be normal, suspicious or abnormal outcome of fetus, however, the result is the same as FHR score, thus, it is not included in clinical FHR diagnostic computer. The ratio of Acceleration duration/movement Burst duration (A/B) ratio, namely, the Apgar score was less than 7 when A/B ratio was less than 1 , however, the result was overlapped to the results of FHR score, thus, it did not included in common computerized FHR diagnosis.

\section{Discussion}

The hypoxia index was composed on the facts of vague outcome of scarce and frequently repeated late decelerations. Although "Cerebral palsy" is a summarized disease name [2], the cerebral palsy and normal cases were grouped also according to the facts. Two groups of hypoxia index were composed of "cerebral palsy" and "no cerebral palsy" cases, which were suitable to separate two groups separated by a clear numeric threshold, which was severely requested to estimate the outcome of fetal monitoring. However, statistic technique was established, namely, the threshold is hypoxia index, which is similar to Apgar score, which is a single numeric score. The target is a disease or one simple numeric data, for example estimate Apgar scoe or umb $\mathrm{pH}$ by the hypoxia index, and so on. It was problem to decide fetal outcome by observers visual classification. The method allowed observers difference and vague results. That was FHR pattern classification after Hon [1] till present in 60 years.

Numeric decision was made by Maeda's FHR score which predicted Apgar and UApH [3,4]. Frequency spectrum analysis decided pathologic sinusoidal FHR [5]. FHR score, hypoxia index and FHR frequency spectrum will be sufficient at present. Such simple computer composed 3 parameters is constructing. Past pattern diagnosis prevented severe asphyxia and fetal demise, but not cerebral palsy, which are possible by the hypoxia index, if it is tried to prevent severe asphyxia. Although the FHR pattern prevented fetal demise, but neither Apgar score nor $\mathrm{UApH}$, which is done by FHR score [4]. The regression equation is useful. Every diagnosis should be done by three parameters. Even deceleration removal is recommended by lateral posture of parturient woman. The new field is wide in update fetal monitoring.

\section{Conclusion}

New field is open in FHR monitoring by numerical criteria to prevent infantile cerebral palsy with hypoxia index and other update mathematical analysis, instead of subjective fetal outcome estimation with FHR deceleration pattern classification .It is suitable to introduce mathematical analysis into computerized studies, although it is able to be studied with manual calculation.

\section{References}

1. Hon EH (1968) An Atlas of Fetal Heart Rate Patterns. Harty Press, New Haven, USA.

2. Volpe JJ (2001) Neurology of the Newborn. In: ( $4^{\text {th }}$ edn), Saunders, USA.

3. Maeda K, Kimura S, Nakano H, et al (1969) Pathophysiology of Fetus, Fukuoka Printing, Fukuoka, Japan.

4. Maeda K, Noguchi Y, Matsumoto F, Nagasawa T (2006) Quantitative fetal heart rate evaluation without pattern classification: FHR score and artificial neural network analysis. In: $\left(2^{\text {nd }}\right.$ edn), In: Kurjak, Chervenak (Eds.), Textboook of Perinatal Medicine, London, UK, pp. 1487-1495.

5. Maeda K, Nagasawa T (2005) Automatic computerized diagnosis of fetal sinusoidal heart rate. Fetal Diag Ther 20(5): 328-334. 
This work is licensed under Creative Commons Attribution 4.0 License DOI: 10.19080/JGWH.2019.14.555891

\section{Your next submission with Juniper Publishers} will reach you the below assets

- Quality Editorial service

- Swift Peer Review

- Reprints availability

- E-prints Service

- Manuscript Podcast for convenient understanding

- Global attainment for your research

- Manuscript accessibility in different formats

( Pdf, E-pub, Full Text, Audio)

- Unceasing customer service

Track the below URL for one-step submission https://juniperpublishers.com/online-submission.php 